\title{
Field demonstration of automated demand response for both winter and summer events in large buildings in the Pacific Northwest
}

\author{
Mary Ann Piette • Sila Kiliccote • \\ Junqiao H. Dudley
}

Received: 3 September 2012 / Accepted: 10 December 2012 / Published online: 28 May 2013

(C) The Author(s) 2013. This article is published with open access at Springerlink.com

\begin{abstract}
There are growing strains on the electric grid as cooling peaks grow and equipment ages. Increased penetration of renewables on the grid is also straining electricity supply systems and the need for flexible demand is growing. This paper summarizes results of a series of field test of automated demand response systems in large buildings in the Pacific Northwest. The objective of the research was twofold. One objective was to evaluate the use demand response automation technologies. A second objective was to evaluate control strategies that could change the electric load shape in both winter and summer conditions. Winter conditions focused on cold winter mornings, a time when the electric grid is often stressed. The summer test evaluated DR strategies in the afternoon. We found that we could automate both winter and summer control strategies with the open automated demand response communication standard. The buildings were able to provide significant demand response in both winter and summer events.
\end{abstract}

Keywords Demand response - Automated demand response - OpenADR - Dynamic peak load reduction

M. A. Piette $(\bowtie) \cdot$ S. Kiliccote $\cdot$ J. H. Dudley

Lawrence Berkeley National Laboratory,

Berkeley, CA, USA

e-mail: mapiette@lbl.gov
Abbreviations
DR Demand response
FERC Federal Energy Regulatory Commission
BPA Bonneville Power Administration
SCL Seattle City Light
HVAC Heating ventilation and air conditioning
CPP Critical peak pricing
EMCS Energy management control systems
DRAS Demand response automation sever
OATR Outside air temperature regression
SMT Seattle Municipal Tower
CLIR Client Logic Integrated Relay
IT Information Technology

\section{Introduction}

Demand response (DR) is a demand-side management strategy to reduce electricity use during times of highpeak electric loads or when prices are high. The Federal Energy Regulatory Commission describes DR as "changes in electric usage by end-use customers from normal consumption patterns in response to changes in the price of electricity over time, or to incentive payments designed to induce lower electricity use at times of high wholesale market prices or when system reliability is jeopardized" (Brattle Group et al. 2009). 
Technology to automate DR has been developed to improve the performance of DR programs by allowing the response to be more repeatable and reliable. This paper describes a set of field tests to evaluate the installation and performance of building control strategies that use a recently developed interoperable information exchange specification to enable fully automated DR. This automated DR signaling system is known as OpenADR, or the Open Automated Demand Response standard (Piette et al. 2009). OpenADR uses utilityprovided price, reliability, or event signals to automatically trigger customers' pre-programmed energy management strategies.

This paper describes DR strategies used for both hot summer afternoons as well as cold winter mornings, both periods when electricity demand is typically high in the Pacific Northwest. The overall goal of the research was to develop, demonstrate, and evaluate automated DR technologies and strategies for commercial buildings in the Pacific Northwest. DR is an important least-cost resource for the northwest's Bonneville Power Administration (BPA) to meet peak demand. Although BPA has historically been able to meet peak load through the flexibility of its hydro system, continued load growth, wind power integration, and fish operations are stretching this capacity. DR is a proven resource that can add both flexibility and capacity back to BPA's system. The tests were held in partnership with Seattle City Light (SCL), the municipal utility in Seattle, Washington.

The research described in this paper covers three primary areas. First, we describe the automation and communications technology used in the study. Second, we describe the methodology to collect wholebuilding electric load data and estimate the reduction in electricity use during the DR events. Third, we describe the five buildings included in the study, providing a description of the heating, ventilation and air conditioning (HVAC) plus lighting systems that were used to automate the DR. The paper is organized as follows. The next section provides background and a summary of previous related DR research in commercial buildings including a summary of automation, electric load baselines, and literature on control strategies in non-residential buildings. The third section presents the methods used in the field study. The fourth and fifth sections cover results and discussions, with a final conclusion summarizing key lessons learned. This paper does not cover the cost analysis to install the automation, which was covered in the original project report (Kiliccote et al. 2010).

\section{Background and previous research}

Initial research on automated DR communications systems by the authors began in 2002 at the request of the California Energy Commission to help develop low-cost automation technology to reduce the possibility of future grid black outs. Another motivation for the automation was to assist the state to move toward dynamic electricity pricing to ensure that customers could automatically respond to high and varying prices. Such high prices might be provided to customers on hot summer days if the electric grid is near capacity (Borenstein 2005). Initial field tests of the DR automation systems began in 2003 with a field study in five buildings (Piette et al. 2005). Early research consisted of development and testing of communications technology as well as building controls strategies. Initial research has identified resetting zone temperatures as a promising technique to modify cooling loads on hot summer days (Motegi et al. 2007). Previous research has included evaluating different HVAC systems as well as examining the use of thermal mass to pre-cool buildings (Yin et al. 2010). DR strategies for lighting systems vary based on the type of controls (Rubinstein and Kiliccote 2007). Research in Canada evaluated human factors with changes in light levels to understand if occupants could detect changes in set points. This work found that while some changes in lighting levels were detectable, it also demonstrated that they were acceptable to occupants tested in controlled environments (Newsham and Birt 2010). There has also been extensive research on developing baseline models to measure the change in electric loads from DR strategies (Goldberg and Agnew 2003). For commercial buildings, the outside air temperature regression baseline tends to be more accurate and less biased baseline than other models used by electric utilities (Coughlin et al. 2009).

DR program evaluations have shown that customers have limited knowledge of how to operate their facilities to reduce their electricity costs under critical peak pricing (Quantum Consulting Inc. and Summit Blue Consulting and LLC. Working Group 2 Demand Response Program Evaluation-Program Year 2004). A similar challenge is that about $15 \%$ of the time, the 
person in charge of responding to the DR events is not at the facility, which is a significant obstacle to reliable manual response to DR signals (Quantum and Summit Blue 2004).

One objective of the automated DR systems was to provide automation at low cost by leveraging existing communications. Previous work has demonstrated how price-response can be automated using standard extensible markup language-based communications with customer-owned control systems. The control systems were not retrofitted, only programmed for DR strategies. Fully automated DR accounts for more than $250 \mathrm{MW}$ of peak demand savings in California. While this paper uses the OpenADR 1.0 technology, OpenADR 2.0 is just emerging as part of the National Institute of Standards and Technology Smart Grid Standards in the USA (OpenADR and OpenADR 2.0 Profile Specification, A Profile. Revision number 1.0. Document: 20110712-1. August 2012). Figure 1 shows the basic architecture of OpenADR, which uses a client-server two-way architecture. The OpenADR clients linked or embedded in the building control system continuously, or every minute, receives signals from the communication server and responds that it has received the signal. The signals also contain "event pending" information to allow a control strategy to prepare for an event by using pre-cooling or preheating systems. OpenADR 1.0 provides an open application program interface for both the client and the communication between the utility system and the server.

The automation server shown in the figure above can be located in the utility offices or at a remote data

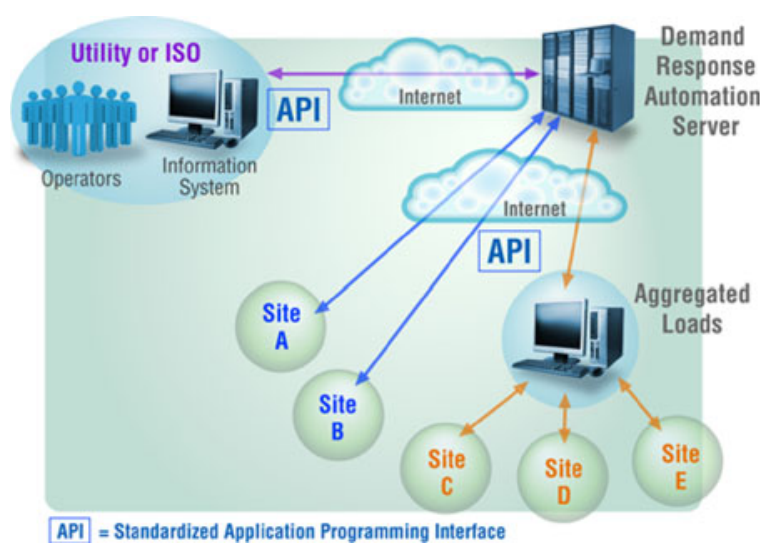

Fig. 1 OpenADR client-server design uses an open application programming interface center. The OpenADR servers in California are located in San Rafael but provide the automation for southern and northern California through an agreement with a private company managing the system. The graphic shows a generic "aggregated load" which can also be geographically distributed. There is an aggregation company in San Diego that uses this model to provide OpenADR-based automation to small commercial buildings. The server in this case, as mention, is in northern California but the sites are in southern California. Given OpenADR tends to use Internet communications, the clients and services can be geographically distributed.

The electricity prices modeled in OpenADR programs have covered a variety of price information. The first pilots in the 2006 and 2007 translated critical peak pricing (CPP) that was offered from May through October in California. CPP tariffs had a normal, moderate and highprice period. The normal period was the majority of the hours. Moderate prices were fixed for noon to $3 \mathrm{pm}$ in the afternoon and the moderate price was three times higher than the normal prices. The high price period was from 3 to $6 \mathrm{pm}$ and was five times the normal price. The OpenADR signal provided normal-, moderate-, and high-price proxy information. OpenADR has a diverse set of data representations that can be customized by a utility to represent information in their DR program. OpenADR has, for example, a full representation of integer values such as $\$ 0.25 / \mathrm{kWh}$ to be provided in an OpenADR signal. The signal can contain "event pending" information that can inform a control system to prepare for a high price event that will occur the following day.

\section{Methodology}

This section outlines the design of the field test including a description of the recruitment of the sites, the automation systems, DR events and analysis methods including DR baselines for estimating the peak demand reduction.

\section{Sites}

The project began with a recruitment phase that included the development of outreach materials for potential participants, surveys of existing electricity loads, and an assessment of 15-min electric load data for winter and summer periods. The first winter tests 
were conducted in the early months of 2009. The summer tests were conducted in summer 2009. Five commercial building sites were recruited with a negotiated memorandum of understanding that described the sequence of the field tests. We collected building systems descriptions using a common site audit format and collected mechanical and electrical drawings when available. Most of the sites provided control system trend logs relevant to the analysis of the DR strategies. Each site had archived data from electric meters. In one case we installed an electric meter for the duration of the project. Each site was offered $\$ 3,000$ for setup to join the project and $\$ 1,000$ for participating in each event in the winter and $\$ 2,000$ for setup and $\$ 500$ for participating in each event in the summer. Although the summer incentives were smaller, all participants from the winter tests took part in the summer tests.

\section{Automation}

The DR signals for this project were published on a DR automation web services server, available on the Internet using the OpenADR signals. Each of the five participating facilities monitored the DR signal using a Web services client application and automatically shed site-specific electrical loads when the proxy price increased. This project demonstrated use of the Open Automated Demand Response Communication Specification (version 1.0), which is designed to facilitate DR automation without human intervention (Piette et al. 2009). Each site was outfitted to receive price proxy signals (or the associated operational mode signals) by one of two methods. If the site can host an embedded client in the energy management control system (EMCS) software implementation is preferable. If no such controls were present a Client Logic Integrated Relay (CLIR) box would be installed (Piette et al. 2006). Each facility's EMCS vendor was hired to program the load-shed or shift control strategy to respond to the increase in the price signal.

During the winter and summer test periods SCL system operators determined the event start and end times. The DR automation server (DRAS) was programmed to send the DR test notifications to each participant. Winter DR events started at 7 a.m. and ended at $10 \mathrm{a} . \mathrm{m}$. The events were dispatched based on the minimum outside air temperature during the DR period. At the beginning of each week, DR events were scheduled for the coldest days of the week as predicted in weather forecasts. Summer DR events started at noon and ended at 5 p.m. The summer events were called when the forecast temperature exceeded $26.7^{\circ} \mathrm{C}$ although one DR event was dispatched on a $25.6{ }^{\circ} \mathrm{C}$ day because the team thought that there would not be any warmer days during the period.

For day-ahead tests, participants received notifications at 3 p.m. previous day, and, for day-of events, participants received notifications $30 \mathrm{~min}$ prior to the event start time. There were a total of four test events for each season: three day-ahead tests and one day-of test. During the winter tests, the test days for each site did not coincide because sites were tested as soon as they were enabled so the team could capture the coldest mornings. During the summer tests, sites were enabled around the same time, so more sites participated in each test event.

Each site was provided a prioritized list of potential DR strategies for the DR events. The price signals can be changed to "normal," "moderate," or "high," and the DR strategies can be tested as the price signals are changed. Commissioning this system entailed changing the price signals and observing the EMCS response. As soon as communication was established, the DRAS operator was notified so that the communications could be verified from the DRAS operator screen. Each site had a "mysite" automation page to allow facility managers monitor the status of signals coming into their control systems.

\section{DR events and baselines}

We called a total of 16 summer and winter DR events. Routine checking of the DRAS and client status along with the automated notifications when clients were offline meant that communication problems between the DRAS and clients or other issues related to client software/hardware were identified well in advance of DR events. The operator was responsible for monitoring the DRAS and status of all clients approximately every half hour to verify that there was no loss of communication between the DRAS and its clients. If the client went offline, the customer were notified immediately to resolve any problems. We collected historical and event day electric load data for each site as well as outside air temperature data from the $\mathrm{Na}$ tional Oceanic and Atmospheric Administration. 
These data were used to develop the three baselines model further described below:

- Outside air temperature regression (OATR) model,

- The "three-in-ten" baseline model, and

- The "average of similar days" baseline model.

The OATR baseline model is the most accurate, least biased model among the three for weathersensitive buildings. However, collecting weather data from a site or a location close to a site is cumbersome and many electric utilities are unwilling to create weather-normalized baselines. Therefore, the threein-ten baseline model, which uses average hourly load shape of the three highest energy-consuming days during the ten work days preceding the DR event of interest, is the baseline model preferred by utilities in California. Developing the three-in-ten baseline does not involve collecting weather data, which simplifies the development process. The demand savings estimates for most of the buildings that participated in the study are based on the baseline OATR model. The exception is one building, which did not have historical electricity use data. For that building for the first events the average-of-similar-days model was used based on as many non-DR days as were available. If the model predicts a lower baseline than the actual demand for any given 15-min or hourly period, this indicates negative demand savings. Negative demand savings are often found after a DR period as part of a "rebound" or recovery peak in which the HVAC system tries to bring the thermal zones back to normal conditions.

The evaluations performed include quantifying the demand savings in kilowatts at each site along with the savings in whole-building power reduction by percentage, and the demand intensity (in watts per square meter). The demand savings are calculated by subtracting the actual whole-building power from baseline demand. The demand savings percentage is defined as the percentage of savings in whole-building power. The demand-savings intensity (in watts per square meter) is the demand reduction (in watts) normalized by the building's floor area (in square meters).

The model to calculate the summer afternoon demand reductions uses OATR with a scalar adjustment for the morning load (noted as OATR-Morning Adjusted, or OATR-MA in the graphics below). This methodology was utilized for the summer tests. However, for the winter tests, because the morning periods are when the Seattle DR events took place, a morning adjustment component was replaced and tested with an afternoon adjustment component because the afternoon periods capture and represent internal loads.

Outside air temperature regression model baseline

The electric consumption for the DR event period was subtracted from the baseline-modelled demand to derive an estimate of demand savings for each 15-min period. Previous research recommends a weathersensitive baseline model with adjustments for morning load variations for accuracy (Goldberg and Agnew 2003). For the OATR baseline, a whole-building power baseline was estimated first using a regression model that assumes that whole-building power is linearly correlated with outside air temperature. The model is computed as shown in Eq. 1:

$L_{i}=a_{i}+b_{i} T_{i}$

where $L_{i}$ is the predicted 15 -min interval electricity demand for time $i$ from the previous non-DR event workdays. Depending on the time interval of the available weather data, $T_{i}$ is the hourly or 15-min interval outside air temperature at time $i$. The parameters $a_{i}$ and $b_{i}$ are generated from a linear regression of the input data for time $i$. Individual regression equations are developed for each 15-min, resulting in 96 regressions for the entire day $(24 \mathrm{~h} /$ day, with four $15-\mathrm{min}$ periods/h. Time $i$ is from $0: 00$ to $23: 45$ ). To develop the baseline electricity loads for determining demand savings, 20 "non-demand response" days were selected. These 20 baseline days were non-weekend, nonholiday, Monday through Friday workdays. Input data were 15-min interval whole-building electricity demand and 15-min interval or hourly outside air temperature.

Some utilities have used a three-in-ten baseline for DR savings. The three-in-ten baseline is the average hourly load shape of the three highest energyconsuming days during the most recent ten work days (excluding holidays). The baseline algorithm for this project considers the site electricity consumption from 7 to $10 \mathrm{a} . \mathrm{m}$. for the winter and noon to $5 \mathrm{pm}$ in the summer when selecting the three days of highest consumption prior to a DR event. For commercial buildings, the OATR baseline is a more accurate and less biased baseline than the three-in-ten baseline 
(Coughlin et al. 2009). Figure 2 is an example showing the Seattle Municipal Tower's participation in the March 3 DR event in 2009. The chart shows the actual whole-building power, the LBNL OATR baseline, and the $3 / 10$ baseline. The vertical line at each baseline data point is the standard error of the regression estimate. The vertical lines at 7 and 10 a.m. identify the DR event period. On this day, the three-in-ten baseline is higher than the OATR baseline because there were cooler days during the previous 10 days that were used to develop the baseline.

An OATR baseline with adjustments (OAT_A) might be more accurate. In an OAT_A baseline, an adjustment factor $\left(r_{a}\right)$ is multiplied by each $15-\mathrm{min}$ load. The factor $r_{a}$ is defined as the ratio of the actual to the predicted load during the $4 \mathrm{~h}$ in the afternoon preceding the winter DR event and $4 \mathrm{~h}$ in the morning prior to the summer DR event, as shown in Eq. 2.

$r_{a}=\sum_{i=1}^{n} L_{a, i} / \sum_{i=1}^{n} L_{p, i}$

Where $r_{a}$ is the adjustment factor, $L_{a, i}$ is the actual hourly average load on DR day at the hour's start at $i$ p.m., $L_{p, i}$ is the predicted load by baseline at the hour's start at $i$ p.m., and $n$ is the number of hours which are used for adjustment ( $n=4$ for this analysis).

Average-of-similar-day baseline

For two sites, interval meters were installed 2 days before the test events and the average-of-similar-day baseline was used because of the lack of prior data. For these sites, available data were averaged to develop the baseline. As the events progressed, the average used to develop the baseline included nontest days.

\section{Results}

Five buildings were recruited as listed in Table 1. The sites include two office buildings, two big box retail buildings, and one education facility.

Two participants, Seattle University and SMT, used CLIR boxes to communicate with the DRAS. McKinstry used a gateway device. Target developed a software client and embedded it into its enterprise control system in Minneapolis. Target stores have centralized DR capability through the enterprise control system. As shown in Table 2, two of the buildings are winter peaking and two are summer peaking. Winter baseline data were not available for one of the Target stores. The largest buildings are SMT and Target T0637. Seattle University has significantly lower summer demand intensity because the facility receives chilled water from the campus.

Table 3 lists 21 potential DR strategies that have been used at other facilities. The 12 strategies used in these 5 sites are identified with the winter (W) and summer (S) strategies listed. For building gas heat, the only potential savings from changing zone temperatures would be the savings from fan power in variable air volume (VAV) systems. When the heating set point is reduced, the fans that supply heat to a zone will temporarily slowdown, which reduces electricity demand. The two Target stores with gas heated roof-top units participated with both lighting and HVAC strategies. SMT, which has all-electric heating and chillers for cooling, employed global zone temperature adjustment for both winter and summer with pre-heating and pre-cooling to prepare for the DR event. Only 26 of the 62 floors were programmed for the event due to lack of time for the control system programming. Seattle University, which receives steam and chilled water from the campus, selected preheating as a winter strategy. To do this, they turned off electrical heating units and adjusted temperature set points to reduce demand from the campus supply. McKinstry dutycycled RTUs in the winter, adjusted temperature set points, and reduced lighting in the kitchen area.

\section{Summary of OpenADR technology performance}

By the beginning of 2009 four DRAS clients were operational for the project: two CLIR boxes and two software clients. No outages were experienced during either the winter season or the summer season. The CLIR and the software clients exceeded $99.99 \%$ reliability once the initial installation and integration were complete. There were two minor communicationrelated problems during the project. One was a malfunctioning CLIR box had been damaged during shipment. The box was replaced when communication could not be established. The other problem resulted from a change in the information technology (IT) setup at Seattle University, and the CLIR box was not brought on line by the IT department until the 
Fig. 2 Example of baseline models and actual DR event day electric load for the Seattle Municipal Tower, 3 March 2009
Seattle Municipal Tower, 3/3/2009 (Min OAT: $43^{\circ} \mathrm{F}$ )

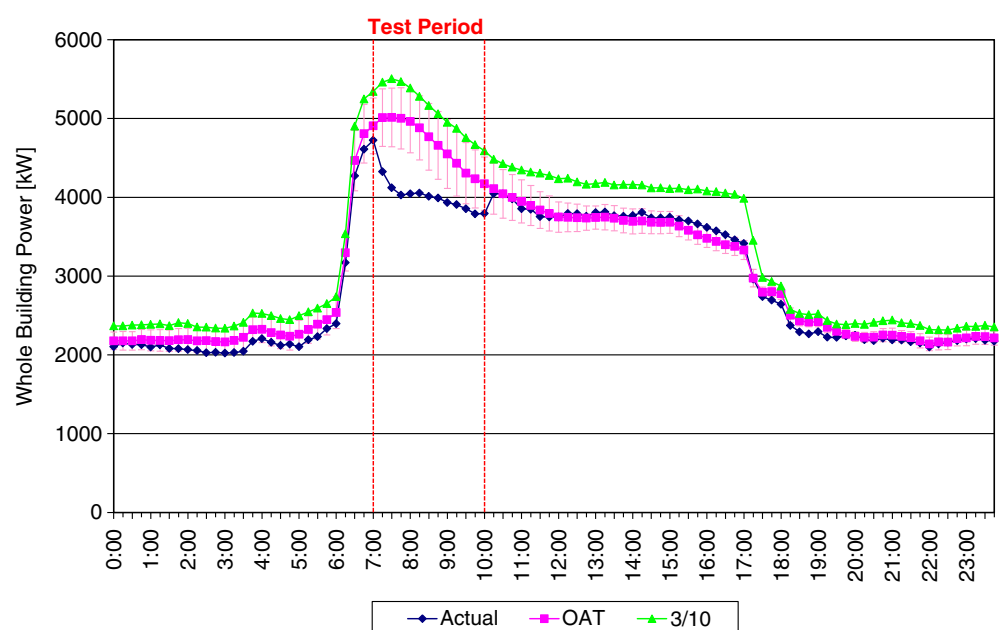

final IT configurations were completed. The delay in that case meant that the site had to trigger events manually until the last event. Thus, the last event called during the summer was the only event that was fully automated at Seattle University.

Summary of event days and conditions

A total of 16 DR events were dispatched based on outside air temperature forecasts in 2009. Table 4 summarizes the DR event days, participation, and outside air temperatures. The first column shows the day of the week on which the site participated in the DR event. The second column shows the date of the event. If a site participated in the event, the cell associated with the date and site is highlighted. The project team wanted to ensure that each site participated in three day-ahead events and one day-of event each season. The last column displays the minimum outside air temperature during the DR period in the winter and the maximum outside air temperature during the DR period in the summer.

\section{Summary of winter results}

The field test described here is the first use of OpenADR employed to enable winter DR. Although Seattle's temperature swings between summer and winter are not extreme, it is a heating-dominant climate, and electric heating is widely used. On average, the buildings that participated in the winter study delivered $14 \%$ demand reduction or $5.5 \mathrm{~W} / \mathrm{m}^{2}$ over

Table 1 Name, type, size, peak demand, and end-use systems in five test buildings

\begin{tabular}{|c|c|c|c|c|c|}
\hline Name & Type & $\begin{array}{l}\text { Gross area } \\
\left(\mathrm{m}^{2}\right)\end{array}$ & $\begin{array}{l}\text { Peak load } \\
(\mathrm{kW})\end{array}$ & Lighting & HVAC \\
\hline Seattle Municipal Tower & Office & 126,000 & 6,168 & $\begin{array}{l}\text { Centrally scheduled with } \\
\text { sweeps }\end{array}$ & $\begin{array}{l}\text { Electric heat, } 690 \text { VAV boxes, } \\
\text { and } 48 \text { AHUs }\end{array}$ \\
\hline Target T1284 & Retail & 17,500 & 685 & $\begin{array}{l}\text { Central fixture switching } \\
\text { (checkerboard) }\end{array}$ & Gas heat and 15 VAV RTUs \\
\hline McKinstry & Office & 10,530 & 347 & $\begin{array}{l}\text { Centrally scheduled with } \\
\text { sweep }\end{array}$ & $\begin{array}{l}\text { Gas heat with both } 7 \text { VAV and } \\
16 \text { CAV RTUs }\end{array}$ \\
\hline Seattle University & Education & 10,505 & 941 & $\begin{array}{l}\text { Centrally scheduled with } \\
\text { sweep }\end{array}$ & $\begin{array}{l}\text { Electric heat, } 102 \text { VAV boxes, } 4 \text { AHUs, } \\
\text { and cabinet and unit heaters }\end{array}$ \\
\hline Target T0637 & Retail & 10,463 & 225 & $\begin{array}{l}\text { Central fixture switching } \\
\text { (checkerboard) }\end{array}$ & Gas heat and 15 VAV RTUs \\
\hline
\end{tabular}

$V A V$ Variable air volume, $C A V$ constant air volume, $R T U s$ rooftop units, $A H U$ air handler units 
Table 2 Summer and winter peak demand for the five facilities

Winter data for Target Store T0637 were corrupted

\begin{tabular}{llrlll}
\hline Site & \multicolumn{2}{l}{ Summer } & & \multicolumn{2}{l}{ Winter } \\
\cline { 2 - 3 } \cline { 5 - 6 } & $\mathrm{W} / \mathrm{m}^{2}$ & $\mathrm{~kW}$ & & $\mathrm{~W} / \mathrm{m}^{2}$ & $\mathrm{~kW}$ \\
\hline McKinstry & 49 & 522 & & 32 & 347 \\
Seattle Municipal Tower & 38 & 4,921 & & 48 & 6,168 \\
Seattle University & 16 & 176 & & 78 & 841 \\
Target T1284 & 44 & 784 & & 30 & 534 \\
Target T0637 & 30 & 320 & & - & - \\
\hline
\end{tabular}

$3 \mathrm{~h}$. The best-performing winter site was Target [T1284], which consistently delivered $19 \%$ demand reduction. During the winter DR events, the sites delivered, on average, $767 \mathrm{~kW}$ demand reduction, which is $14 \%$ of the peak load (Table 4). The reductions resulted from demand shedding. Because loads were not deferred to other times of the day, 8.6 MWh of energy were saved during the winter DR events (Table 5).

During the winter DR tests, events were dispatched next day following the enablement of each site to capture cold winter morning responses. There was no single event in which all the sites participated. However, on March 11, four out of five sites participated in an event. The minimum outside air temperature during the DR period was $-2.2{ }^{\circ} \mathrm{C}$. Because of a communication issue, data for two sites could not be collected on this date. Figure 3 shows the only aggregated demand savings during the winter tests, for the 5 March event the only event in which all sites participated. Average demand reduction per event of $767 \mathrm{~kW}$ (or $14 \%$ ) was recorded using the outside air temperature baseline on 5 March. This value is calculated by averaging the sum of each test day. The majority of savings results from the large peak demand savings at SMT. In aggregate calculations, the largest load typically dominates the aggregate shape. SMT has the highest loads among the project sites; thus, its load shape dominates the aggregate shape. This load shape is also representative of the winter morning peak problem in Seattle.

Table 3 Summary of DR control strategies

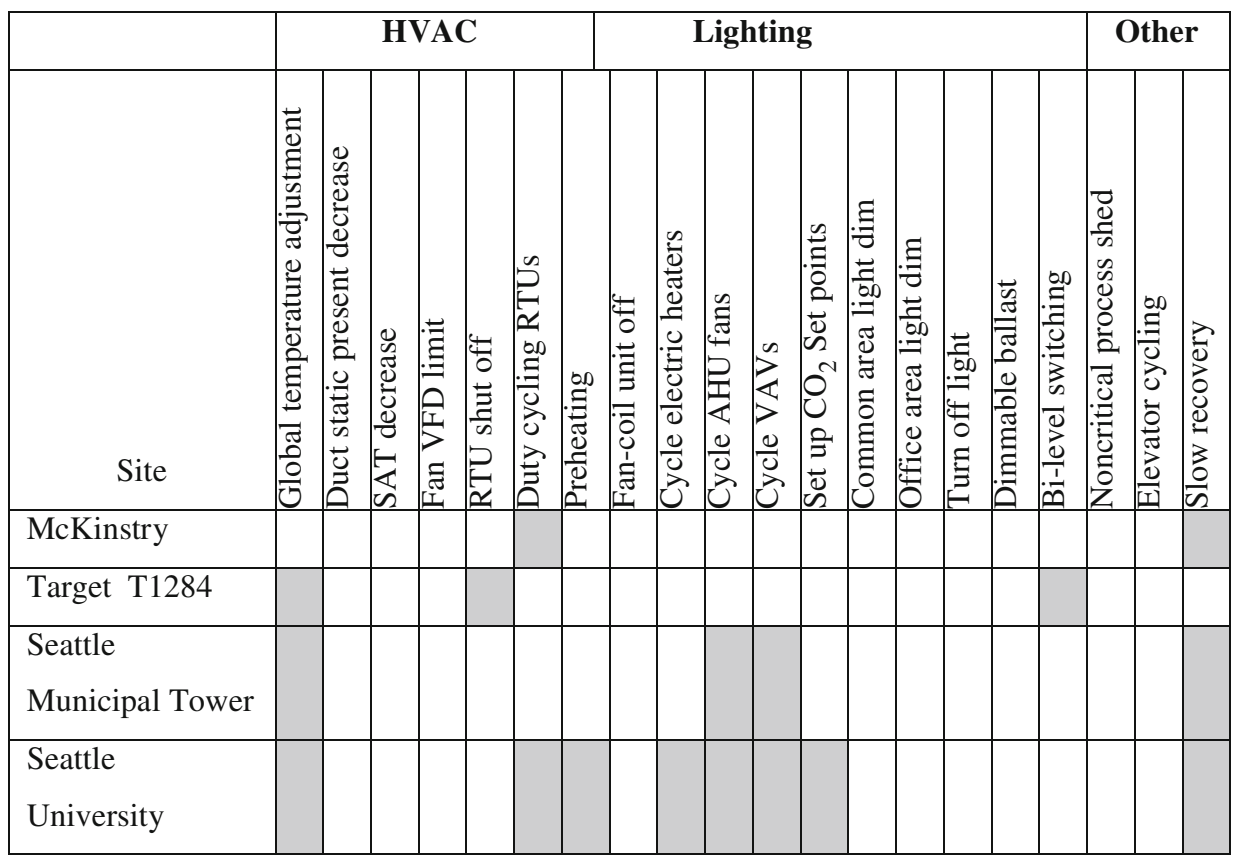


Table 4 Summary of OpenADR winter and summer DR events in 2009

\begin{tabular}{|c|c|c|c|c|c|c|c|c|}
\hline $\begin{array}{l}\text { Day of } \\
\text { week }\end{array}$ & Date & Test & McKinstry & $\begin{array}{l}\text { Target } \\
\text { T1284 }\end{array}$ & $\begin{array}{l}\text { Target } \\
\text { T0637 }\end{array}$ & $\begin{array}{l}\text { Seattle Municipal } \\
\text { Tower }\end{array}$ & $\begin{array}{l}\text { Seattle } \\
\text { University }\end{array}$ & $\begin{array}{l}\text { Outside air } \\
\text { temperature }(\mathrm{C})\end{array}$ \\
\hline Wednesday & $18 \mathrm{Feb}$ & Test 1 & Yes & No & No & No & No & 1 \\
\hline Tuesday & $24 \mathrm{Feb}$ & Test 2 & Yes & No & No & No & No & 1 \\
\hline Tuesday & 3 Mar & Test 4 & No & Yes & No & Yes & No & 6 \\
\hline Thursday & 5 Mar & Test 5 & Yes & Yes & No & Yes & No & 2 \\
\hline Monday & 9 Mar & Test 6 & No & Yes & No & Yes & No & 1 \\
\hline Tuesday & $10 \mathrm{Mar}$ & Test 7 & No & No & No & No & Yes & -2 \\
\hline Wednesday & $11 \mathrm{Mar}$ & Test 8 & Yes & Yes & Yes & Yes & No & -2 \\
\hline Thursday & $12 \mathrm{Mar}$ & Test 9 & No & No & No & No & Yes & -1 \\
\hline Monday & $16 \mathrm{Mar}$ & Test 10 & No & No & Yes & No & Yes & 3 \\
\hline Wednesday & $18 \mathrm{Mar}$ & Test 11 & No & No & Yes & No & Yes & 4 \\
\hline Friday & $20 \mathrm{Mar}$ & Test 12 & No & No & Yes & No & No & 3 \\
\hline Wednesday & 19 Aug & Test 1 & Yes & Yes & Yes & Yes & No & 30 \\
\hline Thursday & 27 Aug & Test 2 & Yes & Yes & Yes & Yes & No & 31 \\
\hline Friday & 11 Sep & Test 4 & No & Yes & Yes & Yes & No & 28 \\
\hline Tuesday & $15 \mathrm{Sep}$ & Test 5 & No & Yes & Yes & Yes & No & 26 \\
\hline Tuesday & 22 Sep & Test 6 & Yes & No & No & No & Yes & 31 \\
\hline
\end{tabular}

Entries set in italics indicate day of DR event

Summary of summer results

The summer OpenADR test was better coordinated than the winter tests, so the sites participated in more events together. Therefore, more aggregated summer event results were calculated. The duration of summer DR events was increased to $5 \mathrm{~h}$ as requested by the SCL operators. The summer study delivered, on average (i.e., average of each site's average), $16 \%$ demand reduction or $4.4 \mathrm{~W} / \mathrm{m}^{2}$ over $5 \mathrm{~h}$ with a cumulative energy savings of $6.5 \mathrm{MWh}$. Table 6 summarizes the performance of each of the sites during these events. The average percent demand reduction at each of the facilities was calculated using the OATR baseline with adjustment for SMT, Seattle University, and Target T1284. For Target T0637, the calculation used an averaging baseline with morning adjustment. For McKinstry, we used the OATR baseline without the morning adjustment because we used pre-cooling as a DR strategy at this facility. Another facility that also practiced 2-h pre-cooling is Seattle University. Historical data for this site are lacking, so we are unable to calculate the OATR baseline, and the averaging baseline falls much below the measured data. Therefore, we used an evening adjustment calculated over $4 \mathrm{~h}$.
Figure 4 shows the aggregated results from the 11 September 2009 (summer) test when aggregate results yielded the best savings. For the sites in the study, the peak occurs around 3 p.m. However, the peak demand is not as pronounced as in the winter. Seattle University is excluded from the aggregate results because that site was not fully automated until 22 September. McKinstry implemented pre-cooling strategies $2 \mathrm{~h}$ before events started. It is recommended that no morning adjustments be used for sites with pre-cooling strategies. Overall the average demand reduction for summer $(338 \mathrm{~kW})$ was more than half of the DR provided by the winter events $(767 \mathrm{~kW})$.

\section{Day-ahead versus day-of DR events}

The amount of time between notification and actual start of a DR event affects the type and magnitude of the response in commercial and industrial facilities. Therefore, one of the four test events each season was scheduled as a day-of event so that we could observe how a facility's response differed between day-ahead and day-of tests. Among the participants, Seattle University implemented pre-heating in the winter and precooling in the summer, and McKinstry experimented 
Table 5 Summary of winter OpenADR tests

\begin{tabular}{|c|c|c|c|c|c|c|}
\hline Site & Test & Test 1 & Test 2 & Test 3 & Test 4 & Average \\
\hline \multirow[t]{3}{*}{ McKinstry } & $\mathrm{W} / \mathrm{m}^{2}$ & 2.3 & 1.5 & 1.4 & 2.5 & 1.9 \\
\hline & $\mathrm{kW}$ & 25 & 16 & 15 & 27 & 21 \\
\hline & WBP $(\%)$ & 9 & 6 & 5 & 10 & 8 \\
\hline \multirow[t]{3}{*}{ Target T1284 } & $\mathrm{W} / \mathrm{m}^{2}$ & 4.7 & & 4.7 & & 4.7 \\
\hline & $\mathrm{kW}$ & 102 & & 104 & & 103 \\
\hline & WBP $(\%)$ & 19 & & 19 & & 19 \\
\hline \multirow[t]{3}{*}{ Seattle Municipal Tower } & $\mathrm{W} / \mathrm{m}^{2}$ & 5.3 & 5.6 & 1.7 & 3.72 & 4.1 \\
\hline & $\mathrm{kW}$ & 678 & 717 & 220 & 477 & 523 \\
\hline & WBP(\%) & 15 & 15 & 4 & 9 & 11 \\
\hline \multirow[t]{3}{*}{ Seattle University } & $\mathrm{W} / \mathrm{m}^{2}$ & 13.1 & 9.5 & 11.8 & 10.4 & 3.3 \\
\hline & $\mathrm{kW}$ & 141 & 102 & 127 & 112 & 121 \\
\hline & WBP $(\%)$ & 20 & 15 & 19 & 17 & 18 \\
\hline \multirow[t]{3}{*}{ All sites } & $\mathrm{W} / \mathrm{m}^{2}$ & & & & Average $^{b}$ & 3.5 \\
\hline & $\mathrm{kW}$ & & & & Total $^{\mathrm{a}}$ & 767 \\
\hline & WBP (\%) & & & & Average $^{b}$ & 14 \\
\hline
\end{tabular}

Sheds are calculated using OATR model with no adjustments

${ }^{a}$ Total value is the sum of the averages for each site

${ }^{b}$ Average value is the average of each site's average

with pre-cooling in the summer; for these sites in particular, it would be instructive to compare the day-ahead results with pre-heating/pre-cooling with day-of results without pre-heating/pre-cooling. Unfortunately, neither McKinstry nor Seattle University participated in any day-of events during the summer. Seattle University did participate in three day-ahead events and one dayof event in the winter with pre-heating. Because the preheating period was short (only about $2 \mathrm{~h}$ ) and started at 5 a.m. (the building start-up time), it was difficult to see significant changes in the demand profile and savings from pre-heating.

Performance of each site

This section presents a series of comments about individual sites. McKinstry was the most challenging
Fig. 3 Aggregate results from the DR event on 5 March 2009

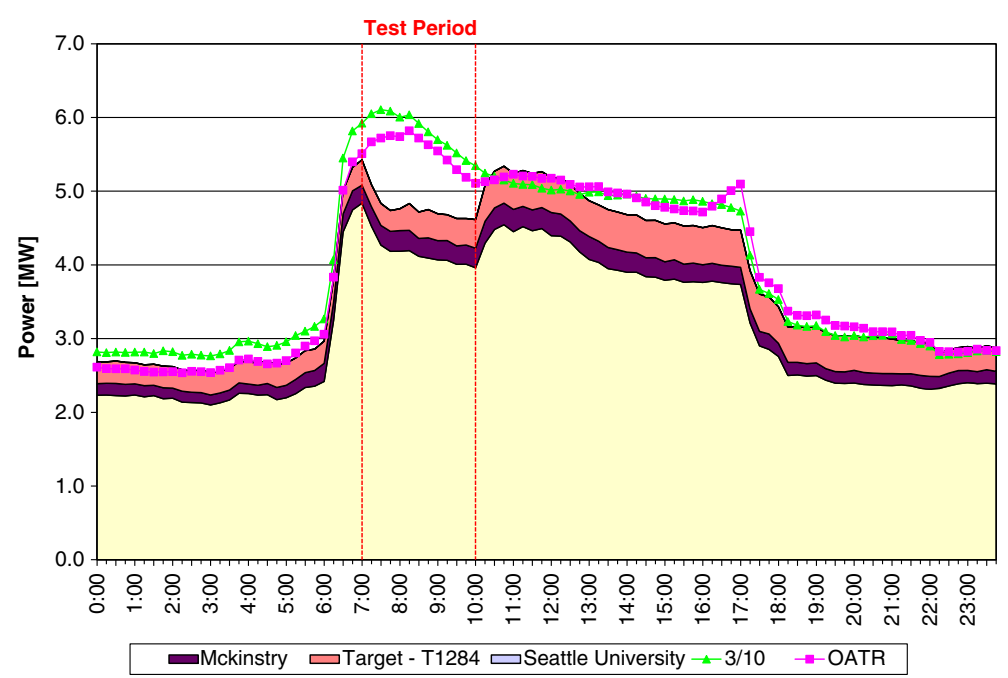


Table 6 Summary of summer OpenADR tests

\begin{tabular}{|c|c|c|c|c|c|c|c|}
\hline Site & Test & Test 1 & Test 2 & Test 3 & Test 4 & Test 5 & Average \\
\hline \multirow[t]{3}{*}{ McKinstry } & $\mathrm{W} / \mathrm{m}^{2}$ & 0.7 & 3.7 & 7.3 & 4.7 & 4.7 & 4.2 \\
\hline & $\mathrm{kW}$ & 8 & 40 & 79 & 51 & 50 & 46 \\
\hline & WBP (\%) & 2 & 10 & 21 & 14 & 13 & 12 \\
\hline \multirow[t]{3}{*}{ Target T1284 } & $\mathrm{W} / \mathrm{m}^{2}$ & 11.5 & 6.6 & 16.0 & 5.3 & & 9.9 \\
\hline & $\mathrm{kW}$ & 205 & 118 & 284 & 94 & & 175 \\
\hline & WBP (\%) & 31 & 22 & 40 & 19 & & 28 \\
\hline \multirow[t]{3}{*}{ Target T0637 } & $\mathrm{W} / \mathrm{m}^{2}$ & 6.0 & 3.8 & 2.9 & 4.9 & & 4.4 \\
\hline & $\mathrm{kW}$ & 65 & 41 & 31 & 53 & & 48 \\
\hline & WBP $(\%)$ & 23 & 18 & 14 & 21 & & 19 \\
\hline \multirow[t]{3}{*}{ Seattle Municipal Tower } & $\mathrm{W} / \mathrm{m}^{2}$ & -1.8 & 1.4 & 1.4 & - & & 0.3 \\
\hline & $\mathrm{kW}$ & -232 & 186 & 180 & 3 & & 34 \\
\hline & WBP (\%) & -5 & 4 & 4 & 0 & & 1 \\
\hline \multirow[t]{3}{*}{ Seattle University } & $\mathrm{W} / \mathrm{m}^{2}$ & & & & & 3.3 & 3.3 \\
\hline & $\mathrm{kW}$ & & & & & 35 & 35 \\
\hline & WBP (\%) & & & & & 21 & 21 \\
\hline \multirow[t]{3}{*}{ All Sites } & $\mathrm{W} / \mathrm{m}^{2}$ & & & & & Average $^{\mathrm{b}}$ & 4.4 \\
\hline & $\mathrm{kW}$ & & & & & Total $^{\mathrm{a}}$ & 338 \\
\hline & WBP (\%) & & & & & Average $^{\mathrm{b}}$ & 16 \\
\hline
\end{tabular}

Sheds are calculated using OATR model with no adjustments

${ }^{a}$ Total value is the sum of the averages for each site

${ }^{\mathrm{b}}$ Average value is the average of each site's average

site. The savings from the winter tests were generally low because the building uses gas heating, so only limited savings were possible from the fans in the small number of RTUs that were cycled. Although small, the winter demand reduction was visible and consistently outside of the standard error of the baseline. On 2 of the 5 days of the summer tests, the building incorrectly went into heating mode; when this was realized, the set points were adjusted manually. The 11 September event was one of the two events when the heating mode was
Fig. 4 Aggregate results from 11 September 2009

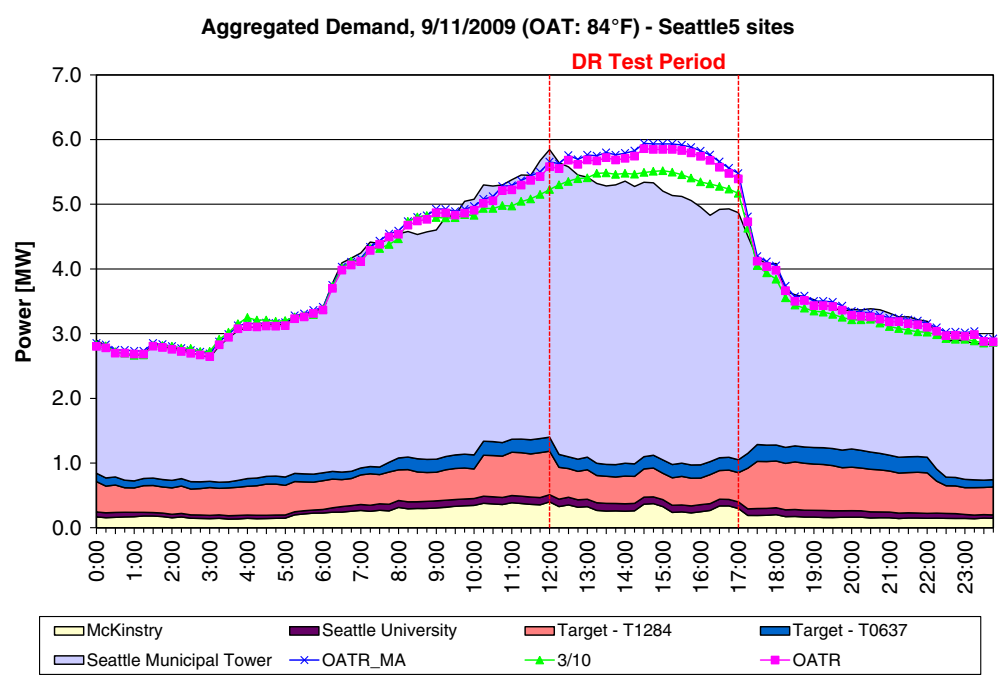


triggered; although significant savings resulted, the facilities group reported receiving many complaints from building occupants.

Target Store staff asked that we exclude lights around the fitting room from DR strategies. The Target team rewired the lights in the fitting room area so that they were excluded from being shut off during the DR events. Trend logs were collected from the controls, including zone temperatures serviced by the 12 RTUs. Figure 5 shows the zone temperatures on August 19. Although it takes 4 to $5 \mathrm{~h}$ for a few of the zone temperatures to increase by $2.2{ }^{\circ} \mathrm{C}$, temperatures in a majority of the zones increased by $2.2{ }^{\circ} \mathrm{C}$ within the first 2 to $3 \mathrm{~h}$ and oscillated around the set point. The observed temperature increase was most rapid in the office and guest services areas and slowest in the pharmacy and conference room areas.

Although Target Store 0637 participated in winter and summer DR events, the winter meter data were corrupted, so we had to exclude them from the winter results (Kiliccote et al. 2010). However, this site continued to participate in DR events during the summer, and the meter data were captured for a few days before the events. Therefore, the averaging baseline was used to calculate the load sheds. This store is smaller than the other Target store in the study, and its load shape is also different. After the shed period, the measured demand was higher than the baseline, indicating a rebound in the first hour and higher demand in the following hours as shown in Fig. 6.

\section{Discussion}

There are a number of key findings from the research that are important lessons for future DR programs and system designs. We list five key findings with a brief discussion of each.

Lighting provides year-round DR and can be automated for winter or summer programs Lighting load-sheds have fast ramp times and thus can provide excellent year-round DR although the change in lighting level is detectable by building occupants. However, centralized controls are necessary for DR with lighting systems, and most lighting control systems are not centralized. Most new lighting control systems that integrate with daylighting in commercial buildings have local closed-loop controls.

All electric heating systems offer good opportunities for winter $D R$ A global zone-temperature adjustment
Fig. 5 Zone temperatures from 19 August 2009 DR event in Target (T1284). The DR event began at 12:00 and ended at 17:00

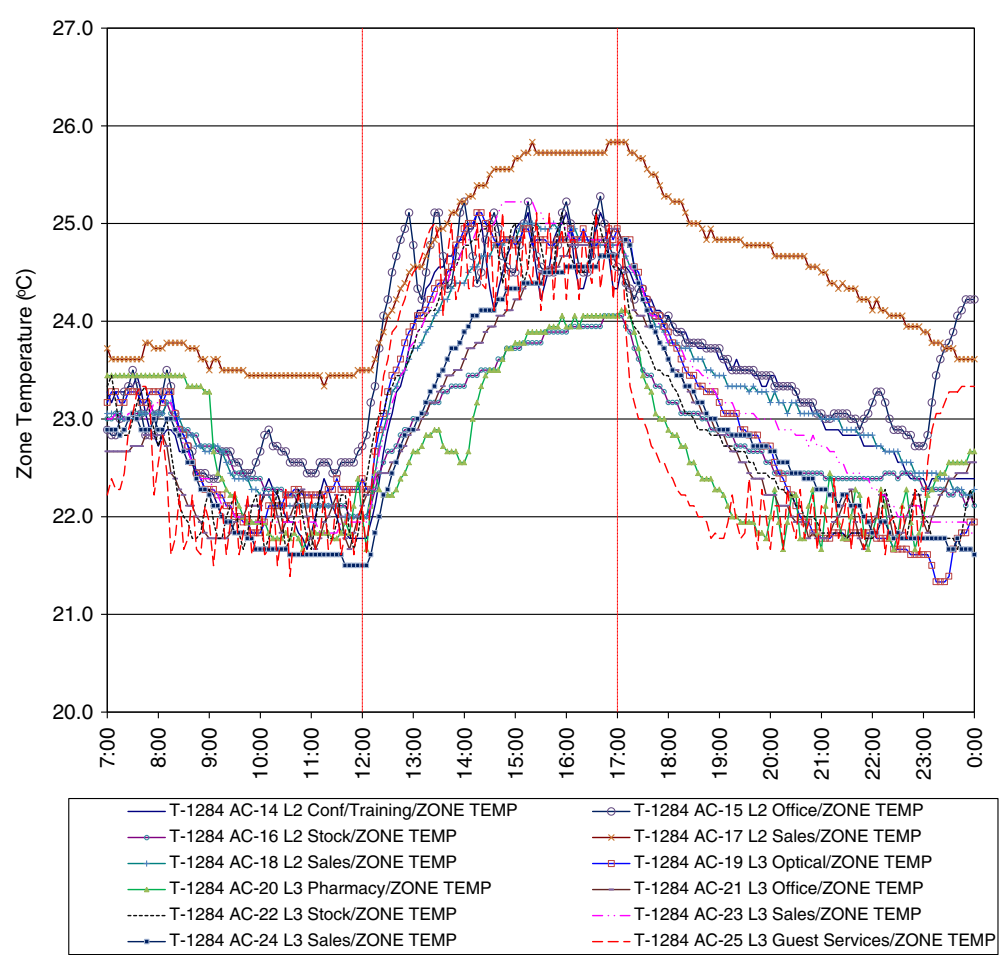


Fig. 6 Min (a) and max (b) peak reductions days for Target (T0637) in 2009 a

Target - T0637, 9/11/2009 (Max OAT: $83^{\circ} \mathrm{F}$ )

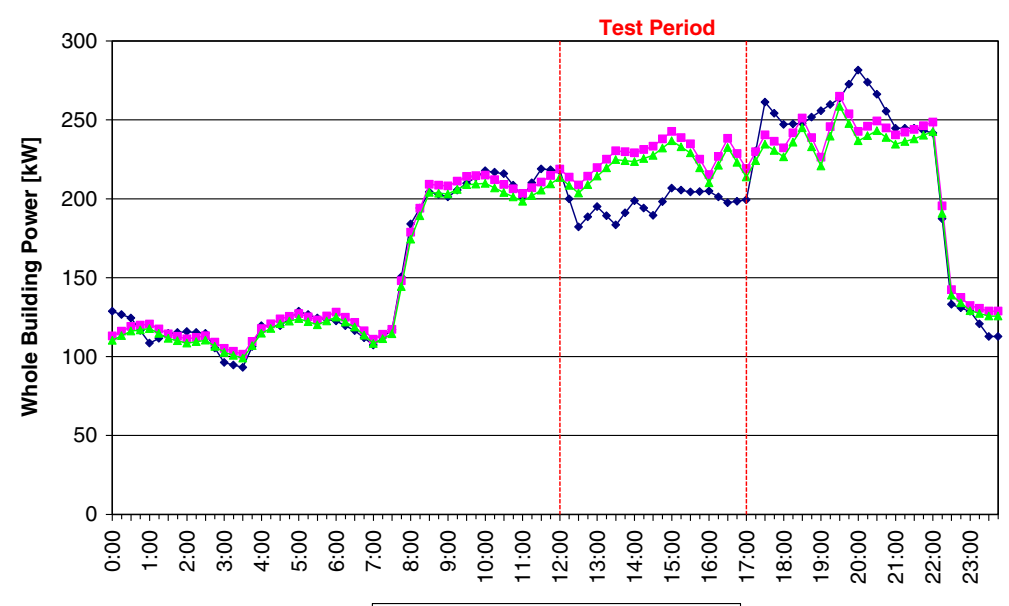

- Actual - - Baseline $₫ 3 / 10 \mathrm{BL}$

b

Target - T0637, 8/19/2009 (Max OAT: $86^{\circ} \mathrm{F}$ )

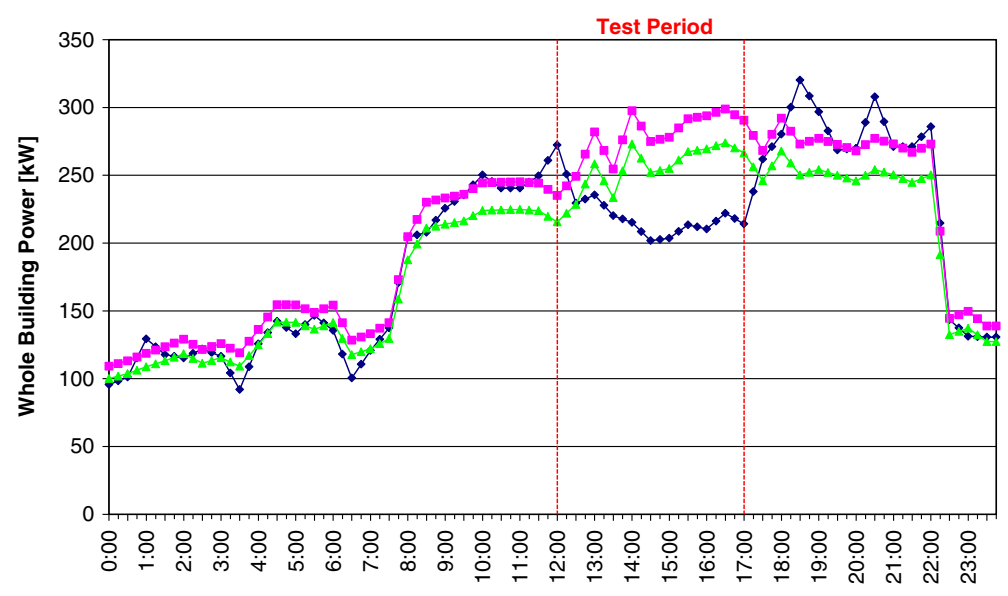

$\rightarrow$ Actual $\rightarrow$-Baseline $\rightarrow-3 / 10 \mathrm{BL}$ strategy, which is often used in California to reduce peak demand during summer afternoons, performed well in the electrically heated building in this study. Zone temperatures were temporarily reduced to minimize electric loads.

OpenADR systems can be used for both winter and summer DR in commercial buildings This project is the only demonstration the authors are aware of in which the control system trigged an automated "winter" or "summer" strategy based on the mode of the HVAC system using OpenADR. On average, using the outside air temperature regression baseline, the buildings that participated in the winter DR events delivered $14 \%$ demand reduction per site or $5.3 \mathrm{~W} / \mathrm{m}^{2}$ over
$3 \mathrm{~h}$. The summer DR events delivered $16 \%$ demand reduction per site or $4 \mathrm{~W} / \mathrm{m}^{2}$ over $5 \mathrm{~h}$. HVAC and lighting systems appear to present major opportunities for automated DR in commercial buildings for both winter and summer loads. In this study, both HVAC systems with electric heating and gas heating provided DR opportunities because there are significant savings from fan power. Average demand reductions for winter and summer events were 730 and $481 \mathrm{~kW}$ or 12 and $8 \%$ of aggregate peak load, respectively.

Commissioning of DR strategies plays an important role in the success of $D R$ in dual-peaking regions During the DR tests, the sites did not have a way to trigger the event-pending signal through their interface ("mysite" 
webpage). The experience from the summer DR tests shows that customers need to be able to replicate all DR operating modes (DR event pending, DR strategy active, and DR strategy idle) to properly commission and test the DR control strategies. A significant finding is the importance of having the ability to trigger the pending signal manually, which was not possible in this test and caused problems for several sites. Commissioning of all of the signals improves the reliability of DR strategies.

DR works best in well-commissioned buildings For one building where the DR performed well in the winter, the summer DR strategies did not perform well because the sequence of operations did not maintain zone temperatures.

\section{Conclusions and future directions}

This study has demonstrated the buildings in some regions of the country can participate in both winter and summer DR events and OpenADR-based automation systems. The controls systems can support DR for both seasons. The majority of research in the USA on OpenADR-based systems has taken place in California and this demonstration shows the capability of these systems to perform in the Northwest. Overall, the average demand reduction for winter $(767 \mathrm{~kW})$ was more than twice that shown for the summer strategies $(338 \mathrm{~kW})$. Additional research is needed to understand how to equipment buildings with these DR automation technologies and allow them to participate in DR programs throughout the USA and internationally. OpenADR 2.0 will allow many control companies to certify clients that are embedded in their control systems. Many utilities will need research such as that shown in this field test to understand the DR resources that commercial buildings can supply.

Acknowledgments The work described in this paper was funded by BPA, by Seattle City Light, and by the US Department of Energy under Contract No. DE-AC02-05CH11231. The authors are grateful for the extensive support from numerous individuals and organizations that assisted in this project. These include the Bonneville Power Administration, Seattle City Light, Akuacom, McKinstry, Target, Seattle Municipal Tower, and Seattle University.
Open Access This article is distributed under the terms of the Creative Commons Attribution License which permits any use, distribution, and reproduction in any medium, provided the original author(s) and the source are credited.

\section{References}

Borenstein, S. (2005). The long-run efficiency of real-time electricity pricing. Energy Journal, 26(3).

Coughlin, K., Piette, M. A., Goldman, C., \& Kiliccote, S. (2009). Statistical analysis of baseline load models for nonresidential buildings. Energy and Buildings, 41, 374-381.

Goldberg, M., \& Agnew G. (2003). Protocol Development for Demand Response calculations: Findings and Recommendations. Prepared for the California Energy Commission by KEMA-Xenergy. CEC 400-02-017F.

Kiliccote, S., Piette, M. A., \& Dudley, J. H. (2010). Northwest Open Automated Demand Response Technology Demonstration Project, LBNL-2573E.

Motegi, N., Piette, M. A., Watson, D. S., Kiliccote, S., \& Xu, P. (2007). Introduction to Commercial Building Control Strategies and Techniques for Demand Response, LBNL-59975, May.

Newsham, G. R., \& Birt, B. (2010). Demand-responsive lighting: a field study. Leukos, 6(3), 203-225. 01-01.

OpenADR Alliance, OpenADR 2.0 Profile Specification, A Profile. Revision number 1.0. Document: 20110712-1. August 2012.

Piette, M. A., Sezgen, O., Watson, D., Motegi, N., Shockman, C., \& Ten Hope, L. (2005). Development and evaluation of fully automated demand response in large facilities, California Energy Commission report 500-2005-013.pdf. January.

Piette, M. A., Watson, D., Motegi, N., \& Kiliccote, S. (2006). Automated Critical Peak Pricing Field Tests: Pilot Program Description and Results. August 2007. LBNL-62218.

Piette, M. A., Ghatikar, G., Kiliccote, S., Koch, E., Hennage, D., Palensky, P., \& McParland, C. (2009). Open Automated Demand Response Communications Specification (Version 1.0). California Energy Commission, PIER Program. CEC500-2009-063, LBNL-1779E.

Quantum Consulting Inc. and Summit Blue Consulting, LLC. Working Group 2 Demand Response Program EvaluationProgram Year. (2004). Final Report. Prepared for Working Group 2 Measurement and Evaluation Committee. Berkeley CA and Boulder CO, December 2004.

Rubinstein, F. M., \& Kiliccote, S. (2007). Demand responsive lighting: a scoping study, LBNL-62226.

The Brattle Group, Freeman, Sullivan \& Co, Global Energy Partners, LLC. (2009). A National Assessment of Demand Response Potential. Federal Energy Regulatory Commission Staff Report, June.

Yin, R., Xu, P., Piette, M. A., \& Kiliccote, S. (2010). Study on Auto-DR and Pre-cooling of Commercial Buildings with Thermal Mass in California. Energy and Buildings 42, No. 7: 967-975. LBNL-3541E. 